\title{
Spatial distribution, feeding damage, and economic impact of grape plume moth (Lepidoptera: Pterophoridae) in commercial vineyards
}

\author{
Greg English-Loeb, ${ }^{1}$ Marc Rhainds, Steve Hesler \\ Department of Entomology, Cornell University, New York State Agricultural Experiment \\ Station, Geneva, New York, United States 14456
}

Tim Martinson

Cornell Cooperative Extension, Finger Lakes Program, Cornell University, County Office Building, Penn Yan, New York, United States 14527-1130

The Canadian Entomologist 134: 137 - 139 (2002)

The grape plume moth, Pterophorus periscelidactylus (Fitch.), an oligophagous insect that feeds exclusively on plants of the genus Vitis L. (Vitaceae), is widely distributed in North America (Whitcomb and Tomlinson 1940, 1943; Jubb 1979). Eggs are laid in late June on 1- or 2-year-old canes of vines, and larvae hatch in May the following year, when young shoots begin to elongate. Larvae construct a shelter by fastening together leaves of young shoots, and feed on lateral leaves, terminal buds, or developing flower clusters. The status of grape plume moth as a pest of cultivated grapes is unclear. Although up to $78 \%$ of young shoots may be infested (Jubb 1979), damage occurs relatively early in the season when shoots are still vigorously growing, and vines may recover from infestation. Regular monitoring of infestation in the spring is recommended to prevent population buildup (Jubb 1979), but the spatial distribution of grape plume moth has never been investigated. Objectives of the present study were to investigate spatial distribution, larval feeding site, and economic impact of grape plume moths in commercial vineyards in the Finger Lake region of New York State $\left(42.5^{\circ} \mathrm{N}, 77^{\circ} \mathrm{W}\right)$.

A survey was conducted in 24 vineyards in 1996 and 11 vineyards in 1997, with either Vitis vinifera L., V. labrusca L. 'Niagara', or interspecific hybrids. For each vineyard, the incidence of damage by grape plume moths was assessed on 20 vines, with 10 shoots examined for each vine; half the vines were sampled $8-10 \mathrm{~m}$ from the edge of wooded areas and the other half $20-25 \mathrm{~m}$ from the edge. For each infested shoot, larval feeding site was classified as a flower cluster, a terminal bud, or lateral leaves. In an experiment assessing the impact of feeding damage on the development and yield of shoots in 1997, four shoots per vine were marked on each of 25 vines, with each shoot having a different type of feeding damage: no damage, bud damage, cluster damage, or leaf damage. Elongation of shoots was assessed by measuring each marked shoot twice approximately 45 days apart. Yield of shoots was quantified by recording the number of berries at harvest. Experiments conducted in 1997 and 1998 assessed the impact of insecticide treatment on damage by grape plume moth and yield of vines, using a completely randomized block design with 12 replicates. For each replicate, one vine was treated with insecticide and one was left untreated; to prevent an edge effect, one vine on each side of the treated vine was also treated. When young shoots of vines were 5$10 \mathrm{~cm}$ long, carbaryl (Sevin 5OW), in 1997, and Bacillus thuringiensis kurstaki (Dipel), in 1998, was applied with a backpack sprayer at the respective rates of 1.3 and $0.12 \mathrm{~g}$ a.i. (grams active ingredient) per vine. For each vine, the proportion of damaged

\footnotetext{
${ }^{1}$ Corresponding author (e-mail: gmel@cornell.edu).
} 
TABLe 1. Mean \pm SE proportion of shoots with different types of feeding injury by Pterophorus periscelidactylus larvae on vines sampled in commercial vineyards 8-10 (edge) or 20-25 (interior) m from the edge of wooded areas.

\begin{tabular}{lccccc}
\hline & \multicolumn{2}{c}{1996} & & \multicolumn{2}{c}{1997} \\
\cline { 2 - 3 } \cline { 5 - 6 } Type of feeding injury & Edge & Interior & & Edge & Interior \\
\hline Flower cluster & $0.036 \pm 0.004$ & $0.018 \pm 0.003$ & & $0.054 \pm 0.012$ & $0.030 \pm 0.008$ \\
Terminal bud & $0.093 \pm 0.009$ & $0.035 \pm 0.004$ & & $0.133 \pm 0.032$ & $0.085 \pm 0.023$ \\
Lateral leaves & $0.182 \pm 0.010$ & $0.091 \pm 0.008$ & & $0.165 \pm 0.041$ & $0.095 \pm 0.029$ \\
\hline
\end{tabular}

NoTE: Data were analyzed using factorial analysis of variance, with feeding injury and distance to woodlots treated as fixed factors and vineyard as a blocking factor. Significance levels were $P$ (feeding injury) $<0.0001$ in 1996 and $1997 ; P$ (distance) $<0.001$ in 1996 and 1997; $P$ (feeding injury $x$ distance) $=0.071$ in 1996 and 0.572 in 1997; $P$ (vineyard) $<0.0001$ in 1996 and 1997. Heterogeneity of variance was reduced by subjecting data to arcsine transformation.

TABLE 2. Impact of feeding injury by Pterophorus periscelidactylus larvae on elongation and yield of Vitis labrusca 'Niagara' shoots.

\begin{tabular}{lcc}
\hline Type of feeding injury & Elongation of shoots $(\mathrm{cm})$ & Number of berries/shoot \\
\hline None & $102.0 \pm 7.1 \mathrm{a}$ & $15.3 \pm 3.6 \mathrm{a}$ \\
Flower cluster & $84.8 \pm 8.0 \mathrm{~b}$ & $4.2 \pm 1.6 \mathrm{bc}$ \\
Terminal bud & $70.3 \pm 7.3 \mathrm{c}$ & $1.5 \pm 1.0 \mathrm{c}$ \\
Lateral leaves & $90.7 \pm 8.2 \mathrm{ab}$ & $9.7 \pm 2.7 \mathrm{ab}$ \\
\hline
\end{tabular}

Note: Mean \pm SE values within a column followed by the same letter are not different (Student-Newman-Keul's test, $P>$ 0.05 ). Heterogeneity of variance was reduced by subjecting number of fruits/shoot to rank transformations.

shoots was recorded before and after insecticide was applied, and the weight of fruit clusters at harvest was measured.

Proportion of damaged shoots in commercial vineyards averaged $0.23 \pm 0.03$ (SE) in 1996 and $0.28 \pm 0.06$ in 1997. Incidence of damage was higher near the edge of wooded areas than in the interior of vineyards (Table 1). In 1996, damage was highest on lateral leaves, intermediate on terminal buds, and lowest on fruit clusters; in 1997, damage on lateral leaves and terminal buds was similar and exceeded that on fruit clusters (Table 1). Feeding damage by grape plume moth larvae significantly affected development and yield of vines on a per shoot basis (Table 2). Of all types of feeding injury, damage on lateral leaves had the least impact on development and yield of single shoots; damage on fruit clusters and terminal buds significantly reduced elongation and yield of shoots, with damage on terminal buds having the most impact (Table 2). Application of carbaryl and $B$. thuringiensis reduced infestation by grape plume moth, but the yield of treated and untreated vines did not differ (Table 3).

The higher incidence of damage by grape plume moth on vines located near the edge of wooded areas than in the interior of vineyards (Table 1) may be due to abundant populations of wild vines, Vitis riparia; a survey conducted in 1996 in woodlots adjacent to 15 vineyards indicated that $63 \pm 4 \%$ of shoots of wild vines were infested with grape plume moth (G English-Loeb, unpublished results). Understanding patterns of spatial distribution has important implications for sampling and management of grape plume moth in commercial vineyards. When monitoring incidence of infestation, growers should pay particular attention to vines located near the edge of wooded areas. When applying insecticides, treating vines near the edge of wooded areas may be sufficient to prevent population buildup. Sampling assessments and control measures should both begin at egg hatch, which is typically synchronized with bud break of vines. 
TABle 3. Proportion of Vitis labrusca 'Niagara' shoots infested by larval Pterophorus periscelidactylus and the yield [weight $(\mathrm{kg})$ of harvested berries] of insecticide-treated and untreated vines.

\begin{tabular}{llccr}
\hline & & \multicolumn{2}{c}{ Proportion of infested shoots } & \\
\cline { 3 - 4 } Year & Treatment* & Before treatment & After treatment & Yield \\
\hline \multirow{2}{*}{1997} & Treated vines & $0.178 \pm 0.044 a$ & $0.011 \pm 0.006 a$ & $4.4 \pm 0.9 a$ \\
& Untreated vines & $0.224 \pm 0.034 a$ & $0.210 \pm 0.031 b$ & $3.1 \pm 1.1 a$ \\
& Treated vines & $0.187 \pm 0.025 a$ & $0.029 \pm 0.006 a$ & $10.9 \pm 0.6 a$ \\
& Untreated vines & $0.155 \pm 0.019 a$ & $0.113 \pm 0.016 b$ & $9.2 \pm 0.9 a$ \\
\hline
\end{tabular}

Note: For each year, mean \pm SE values within a column followed by the same letter are not different $(t$ test, $P>0.05)$. Heterogeneity of variance was reduced by subjecting proportion of damaged shoots to arcsine transformations.

* Treatment consisted of carbaryl in 1997 and Bacillus thuringiensis in 1998.

Grape plume moth larvae caused the greatest reduction in growth and yield of vine shoots when they fed on terminal buds, compared with when they fed on lateral leaves or flower clusters (Table 2). Thus, although the proportions of shoots damaged in 1996 and 1997 were similar, grape plume moth may have reduced the yield of vines to a greater extent in 1997; damage was much more prevalent on lateral leaves than on terminal buds or fruit clusters in 1996, whereas in 1997, the incidence of damage was equivalent on terminal buds and lateral leaves (Table 1). These results highlight the importance of recording both the proportion of infested shoots and the predominant type of feeding injury to assess the potential impact of grape plume moth in commercial vineyards.

Control of grape plume moth has been hypothesized to be difficult, because larvae enclosed within their shelter may be protected from insecticide application (Whitcomb and Tomlinson 1943). The lack of difference in yield between treated and untreated vines following insecticide treatment, despite a reduction in larval densities, suggests either a lack of statistical power or that vines may compensate for damage by grape plume moths by allocating more resource to uninfested shoots. The hypothesis of compensation is indirectly consistent with the findings that larval feeding significantly reduced growth and yield of individual shoots (Table 2). Future studies need to quantify the relationship between density of grape plume moth and yield of vines, to establish the status of grape plume moth as a pest of cultivated grapes.

We thank L Gridley, J Bedient, T Weigle, C Lenzo, and C Marion for technical assistance. The Kaplan Fund provided financial support.

Jubb GL. 1979. Little known grape insect pests. American Wine Society Journal 11: 46-7

Whitcomb WD, Tomlinson WE. 1940. The grape plume moth. Journal of Economic Entomology 33: 372-4

— 1943. The grape plume moth. Massachusetts Agricultural Experiment Station Bulletin 409: 1-13

(Received: 1 May 2001; accepted: 18 October 2001) 